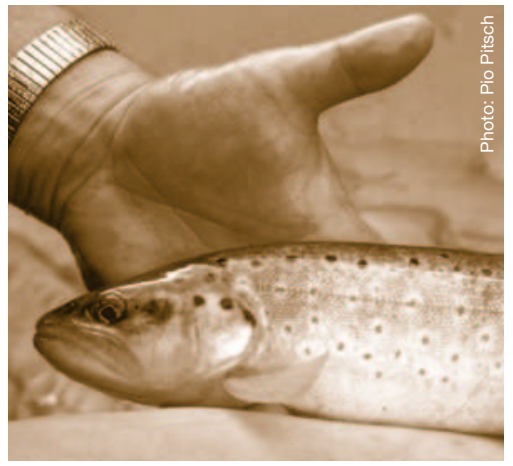

Hydropower is usually considered a relatively "green" energy; it is renewable and does not cause emissions of carbon dioxide or other pollutants. However, outflows of dams often cannot be considered ecologically sound rivers; they are not polluted but altered in their physical regime, mainly through changes in the temporal dynamics of flow and temperature.

During the last decade a paradigm shift has occurred in the way river managers perceive how flowing waters should be managed and restored. Regime-based river management is gaining momentum. Floods are an important natural disturbance, influencing river structure and functioning. In the Spöl River, Switzerland, a flow-regime protocol using experimental floods has been implemented toward restoring river integrity downstream of a large dam. The results suggest that regime-based management has high potential for improving ecosystem integrity while meeting human needs such as power production.

Abstract \& Keywords $\Rightarrow$ p. 232

\title{
Experimental Floods to Improve the Integrity of Regulated Rivers
}

Christopher T. Robinson*, Peter Molinari, Uta Mürle, Johannes Ortlepp,

Thomas Scheurer, Urs Uehlinger, and Margot Zahner

\section{Paradigm Shift in River Management}

Threshold-based management has a long history towards improving the water quality of flowing waters. It was developed to reduce and minimize the concentrations of harmful pollutants in surface waters in an attempt to sustain their ecological function ${ }^{[1]}$. These pollutants are typically point source in origin and man-made toxins that are clearly recognizable by the public and easily controlled when enforced, whereas control of non-point or diffuse pollutants is more difficult. Further, many natural river systems have been regulated to the extent that natural physical (flow, temperature, sediment) and chemical (nutrients) regimes have been altered or eliminated ${ }^{[2]}$. Although the importance of natural regimes (the spatial and temporal variability in physical and chemical conditions) for sustaining river integrity and biodiversity has been recognized ${ }^{[3,4]}$ and even mandated in the European Water Framework Directive ${ }^{[5]}$, regime-based standards in water-management criteria and goals have seldom been implemented [1]. Regime-based standards are likely more dif-

\footnotetext{
* Postal address: PD Dr. C. T. Robinson Department of Limnology

EAWAG/ETHZ

CH-8600 Dübendorf (Switzerland)

E-Mail: robinson@eawag.ch
}

ficult to realize because they must incorporate the spatial and temporal dynamics of the system of interest. However, with current developments in landscape ecology and analysis, regime-based management plans can be effectively and efficiently put to use to assist in restoring and maintaining the ecological integrity of running waters, thereby enhancing and sustaining valuable ecosystem and human services ${ }^{[6]}$.

Flow is one physical feature of rivers that has been altered throughout the history of mankind. Currently more than 40000 large dams worldwide fragment rivers and change up- and downstream flow regimes. In the foreseeable future the number of large dams is likely to remain unchanged and to even increase in some developing countries ${ }^{[7,8]}$. Consequently, floods have been reduced in number and even eliminated in many systems, thus altering the natural flow regime so important in structuring rivers and for the life histories and evolution of biota ${ }^{[4,9]}$. Flushing flows often have been initiated to mobilize and flush fine sediments in rivers below dams [10], however these flows tended to be single floods at different annual intervals and, consequently, not designed to meet the life-history needs of instream biota: For fishery concerns, for example, multiple floods must be released annually for better redd development (distinct local areas of stream bottom used for egg laying, fertilization and incubation) and to create habitat for juvenile fish. Below we present a case study in which such periodic flood flows were initiated to improve the integrity of a river downstream of a major dam. We argue that similar regime-based protocols could be used in many rivers worldwide, in conjunction with thresholdbased criteria, to improve the management of regulated rivers.

\section{The Spöl River}

The Spöl River in the central Alps flows through Italy and Switzerland (Figure 1). More than 80 per cent of its catchment lies within national parks in the two countries. The Spöl eventually flows into the Danube River via the Inn River. Follow-

$$
\text { Excursus 1 }
$$

\section{Threshold- and Regime-Based Criteria}

Threshold-based criteria refer to the maximal concentrations of pollutants, usually toxins and man-made pollutants, in waters below an allowable risk level to biotic health. Regime-based criteria incorporate the spatial and temporal distributions of physical properties of rivers such as temperature and flow regimes in the management goals for running waters, thereby protecting the natural patterns in riverecosystem variability ${ }^{[1]}$. 

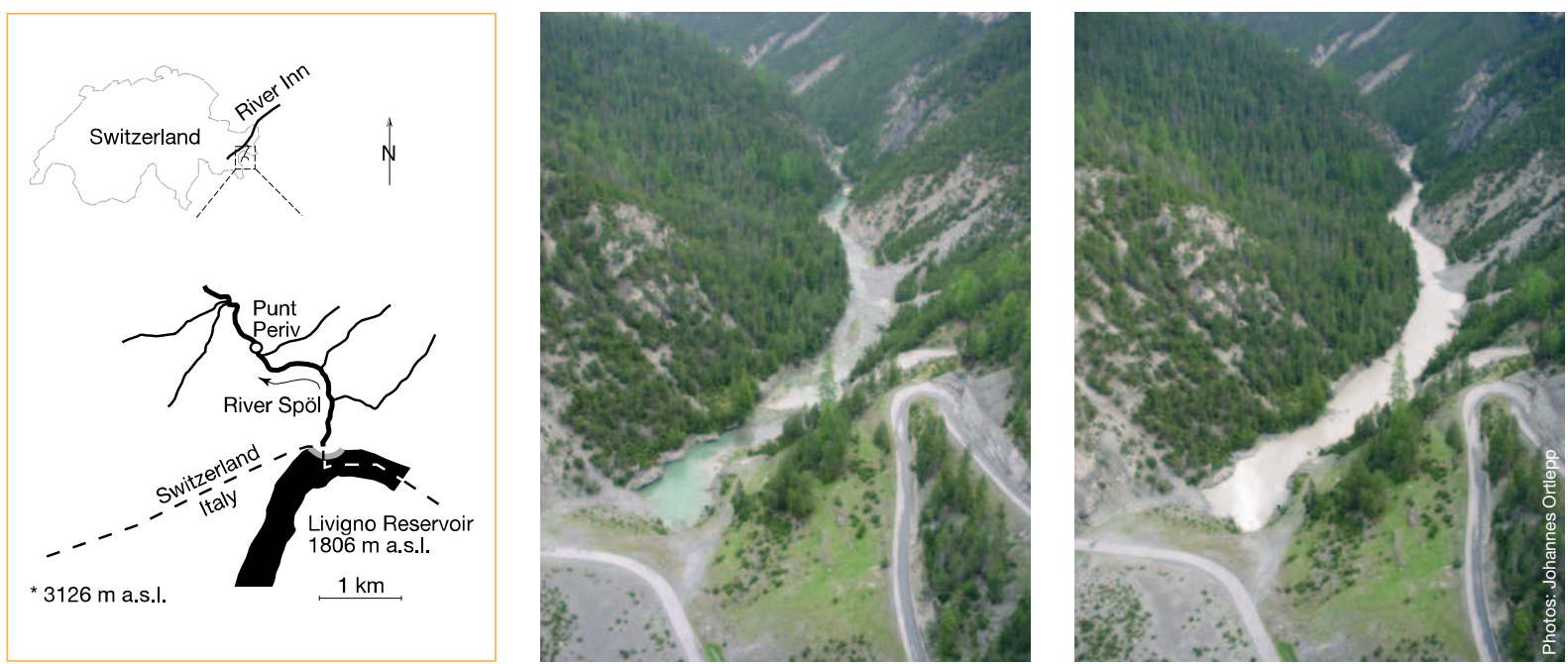

Figure 1. General map of the Spöl River in the Swiss National Park. The photographs show one of the experimental flood discharges from Punt dal Gal dam that retains the Livigno Reservoir. Left photo is at baseflow conditions and right photo is under flood conditions. Note how the scree slopes have extended into the river channel. Map reprinted with permission from Swiss Federal Institute for Environmental Science and Technology (EAWAG) ${ }^{[11]}$.

ing a fierce political campaign in 1956, Switzerland and Italy agreed to use the Spöl for hydroelectric production. The Punt dal Gal dam (forming the Livigno Reservoir) and the Ova Spin dam (Ova Spin Reservoir) were finally completed and started operation in 1970. Both dams are considered large with heights of 130 metres (Punt dal Gal, 164 million cubic metres) and 73 metres (Ova Spin, 6.2 million cubic metres). A complex system of water transfers and reservoir uses allows highly efficient hydropower production. Even the residual flow is used for power production and, therefore, must be held constant.

Before regulation, the Spöl River had average annual flows between 6.6 and 12.5 cubic metres per second and peak flows reaching 36 to 140 cubic metres per second. Following dam completion, flows were regulated at 2.5 cubic metres per second during the day and 1.0 cubic metres per second at night in summer, and at 0.5 cubic metres per second at day and night in winter (Figure 2). Five flushing flows were released between 1970 and 1999, including a large flow in 1970 (up to 125 cubic metres per second), and two smaller ones in 1979 and 1990 (33 to 40 cubic metres per second). Two other small releases ( 10 cubic metres per second) were initiated in 1985 to empty the Livigno Reservoir for servicing purposes and in 1995 for supplementing water to the lower Ova Spin reservoir.

In 1996, the Research Council of the Swiss National Park, the Engadin Hydroelectric Power Company, and the Cantonal and Federal governments agreed to im- plement a flood program to enhance ecological conditions in the Spöl River downstream of the dams and classify its power production as "green" electricity ${ }^{[6]}$. Green electricity is defined as energy produced with low or reduced impacts on the environment. In the Spöl River, residual flow was reduced slightly and the saved water was used for the floods and as compensation for any loss in electrical production, making the project essentially cost-neutral. The program was initially designed as a three-year project to test its long-term management and economic feasibility, to understand ecological effects, and to optimize water usage. Three experimental floods were released each in 2000 and 2001 (two at 11 to 16 cubic metres per second and one at 31 to 45 cubic metres per second), and two in 2002 (52 and 14 cubic metres per second). Besides, high precipitation caused a release flow of 29 cubic metres per second in October 2000 (Figure 2). The smaller floods were sufficient for mobilizing bottom sediments in the Spöl at the beginning of the study; later on, higher flood magnitudes were necessary for the same effect. The floods were released in summer to account for ecology and fishery concerns. The results of the flood program in the river downstream of Punt dal Gal are summarized below.

\subsection{Flood Effects on Stream Habitat}

Because the Spöl River is confined by canyons downstream of the reservoir, flow regulation allowed scree-slope sediments to accumulate and extend into the river channel. Woody vegetation (Pinus mugo and Picea excelsa) also colonized and developed on gravel bars and the river

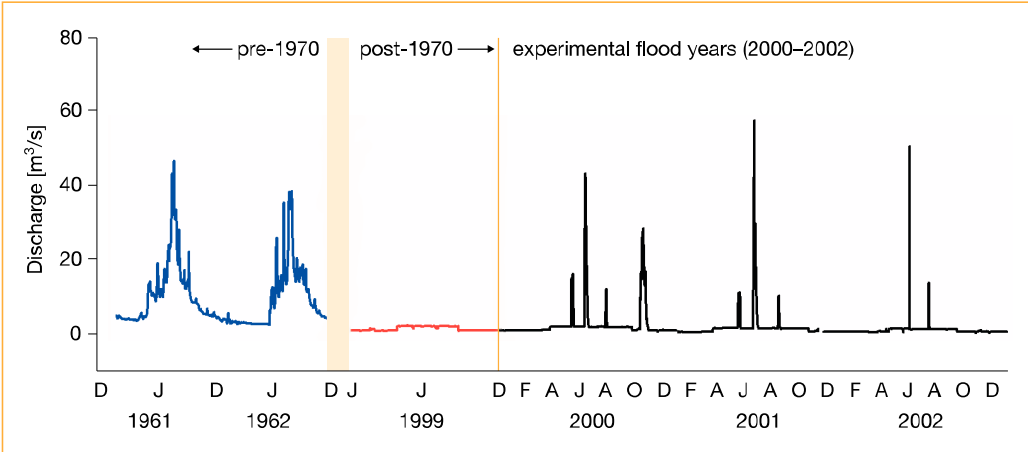

Figure 2. The flow regime in the Spöl River before regulation (pre-1970), after the dam became operational (1970-1999), and during the experimental floods (post-1999). Figure reprinted with permission from Swiss Federal Institute for Environmental Science and Technology (EAWAG) [11]. 


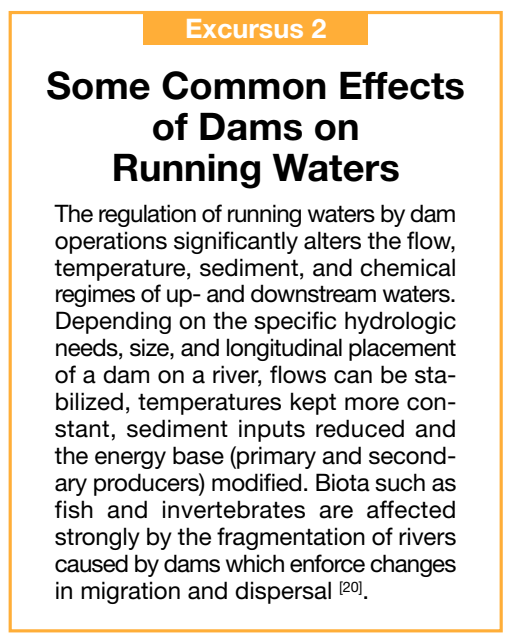

Excursus 3
Summarized Effects
of the Spöl-River
Flood Program
The flood program on the Spöl River
is considered a management suc-
cess. The downstream floods have
enhanced instream habitat heteroge-
neity, increased sediment porosity, and
moderately changed riparian habitats.
These effects allowed recolonization
of some riparian plants, reduced bed
coverage of mosses and filamentous
algae, changed algal composition to
an assemblage dominated by diatoms,
changed macroinvertebrate composi-
tion to an assemblage with more dis-
turbance resistant taxa, and increased
the spawning potential of the fishery
without a loss in fish condition. The
results have caused resource man-
agers to now incorporate floods in the
normal operation of the dam.

banks, and the riverbed became clogged with fine sediments and covered with a thick layer of moss and algae. The floods mobilized fine sediments in the stream bed and transported them downstream. Suspended sediments increased in the initial stages of each flood, and sediment concentrations increased progressively downstream. The floods also eroded debris fans from scree-slopes, sometimes by up to a meter or more (Figure 3 ). The mobilized material was eventually deposited on the riverbed and adjacent riparian areas. The floods transported most fine sediments out of the system and considerably increased the porosity of the streambed. They also enhanced the habitat heterogeneity in the river by increasing the spatial variation in water depths. Subtle changes were observed in riparian vegetation with some floodplain species ab-

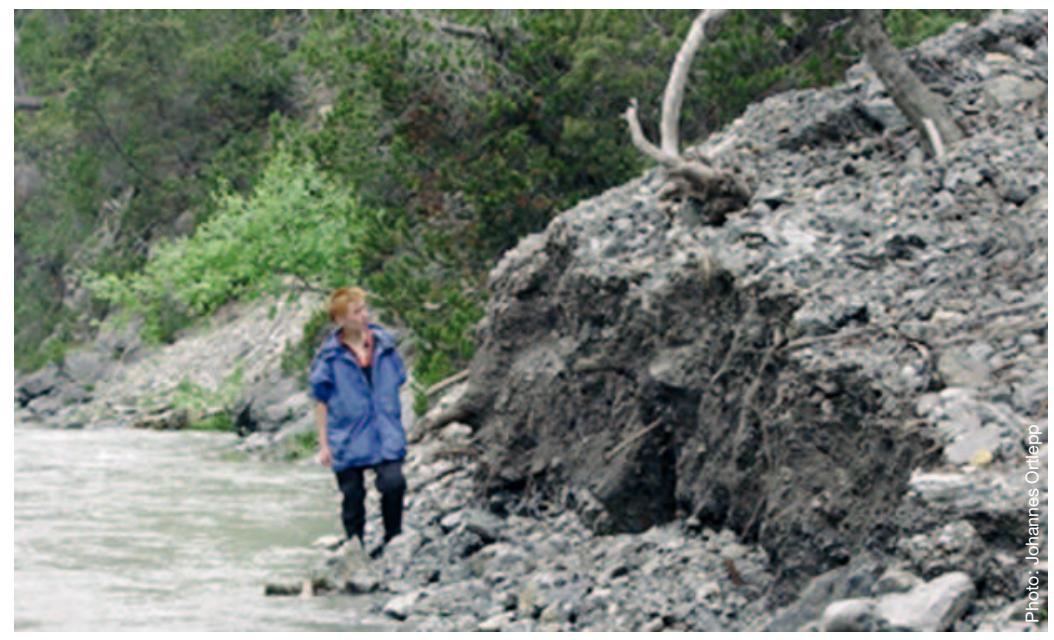

Figure 3. Debris fan originating from a side-slope scree field that was eroded by the experimental floods in the Spöl River, Switzerland.

sent before the floods becoming present afterwards. Woody vegetation was little affected except where banks were strongly eroded. Because deep reservoir water was released from the dam during as well as between floods, essentially no changes were observed in nutrient concentrations or temperature regime.

\subsection{Flood Effects on Instream Moss Cover and Algae}

Abundant patches of mosses on the riverbed were effectively scoured by the floods, resulting in few moss-covered rocks after the third flood in 2000. All floods reduced the biomass of algae in the Spöl River (Figures 4 and 5). However, response patterns in algae following the floods changed among flood years, suggesting a strong sequential effect of the floods. For example, smaller floods had more impact on algal biomass in the initial years than in later years. This difference among years was also reflected in the changes in biomass composition in the Spöl River over time, especially in the loss of mosses and decrease in filamentous algae, and subsequent increase in diatoms (small uni-cellular algae). However, algae always recovered quickly and reached levels as high as or higher than before the floods, perhaps as a compensatory response to increased nutrient availability from the loss of moss. Ecosystem metabolism (measured in terms of oxygen production) increased after the floods, suggesting much of the scoured organic matter and algae were incorporated into the mobilized bed sediments and used by microbes. The floods' primary effect was thus to increase the spatial and, in particular, the temporal variability in algal biomass and composition.

\subsection{Flood Effects on Macroinvertebrates}

The floods reduced the density of benthic macroinvertebrates (invertebrates larger than 100 micrometers in size that inhabit the bottoms of rivers) by up to 90 per cent. Their recovery, however, was rapid after each flood, and densities reached or even exceeded pre-flood densities. A major result of the floods was a change in the composition of the macroinvertebrate assemblage throughout the flood program. For instance, macroinvertebrates that rely on more stable habitat conditions such as the amphipod Gammarus fossarum and the turbellarian Crenobia alpina became less abundant and were replaced by groups that appear more resistant to flow disturbance such as simuliid blackflies and chironomids (Diptera), and baetid mayflies (Ephemeroptera). Some stoneflies (Plecoptera) and caddisflies (Trichoptera) also became more abundant after the floods. This change in composition over time was accompanied by changes in response patterns in the course of the different floods. Low-magnitude floods displayed less of an effect in later years than earlier in the flood program. As a consequence, largermagnitude floods were needed in the later years to have a similar effect on macroinvertebrates as the smaller floods in the initial year. This was probably because of the shift in assemblage structure to more disturbance-resistant organisms.

\subsection{Flood Effects on Fish}

A primary reason for most experimental floods in regulated rivers is to enhance habitat conditions for fish [14]. For instance, the clogging of sediments in the Spöl River from regulated flows decreased the reproductive potential for brown trout, the sole resident fish in the river. The floods 
$568 \pm 495$
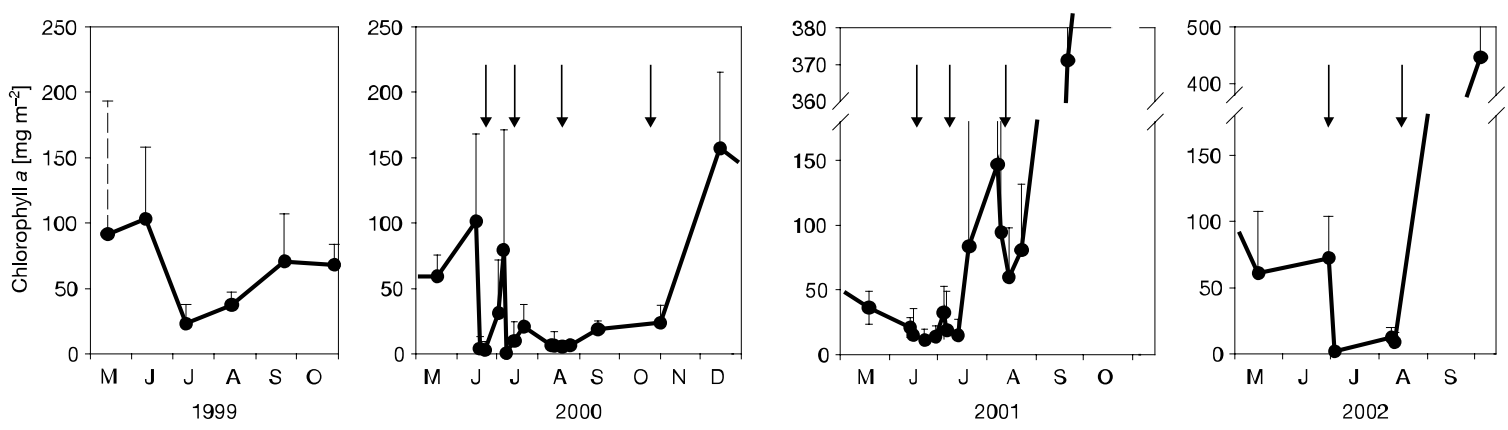

Figure 4. Typical dynamics of algal biomass (measured as Chlorophyll a) before and after the experimental floods (arrows).

Symbols represent averages bounded by standard error bars. Data figure reprinted with permission from Swiss Federal Institute for Environmental Science and Technology (EAWAG) ${ }^{[12]}$.

resulted in the damage or death of relatively few fish (less than two per cent), and the condition (size-weight relationship) of fish remained similar to that before the floods. Although the number of large fish changed little during the flood program, the number of redds made by fish increased three-fold by 2002 (Figure 6). This increase in redds was accompanied by larger numbers of fingerlings being observed in the Spöl River after the floods. We expect that the increased habitat heterogeneity in the Spöl River from the floods will further enhance habitat conditions for trout over time, as trout are known to capitalize on newly created habitats from floods ${ }^{[15]}$.

\section{Perspectives}

The management of flowing waters is in a state of transition, fostered by a paradigm shift from solely threshold-based criteria to incorporation of regime-based criteria in attaining restoration goals of ecosystem integrity and ecosystem services. This development can be seen in recent conceptual developments in riverecosystem ecology. These concepts view rivers and their catchments as holistic ecosystems, recognizing, for example, process domains (importance of different landscape features on river hydrology) in adaptive integrative management ${ }^{[16]}$ or coupling ecological and hydrological processes in ecohydrology ${ }^{[17]}$. The latter concept is an attempt to integrate new interdisciplinary knowledge for the restoration of freshwater ecosystems, as mandated in the European Water Framework Directive ${ }^{[5]}$. The paradigm shift integrates holistic ecosystem principles with human needs to meet present and future threats to running waters globally and to optimize water use in the light of their ecological functions ${ }^{[18]}$. Implementing regime-based cri-

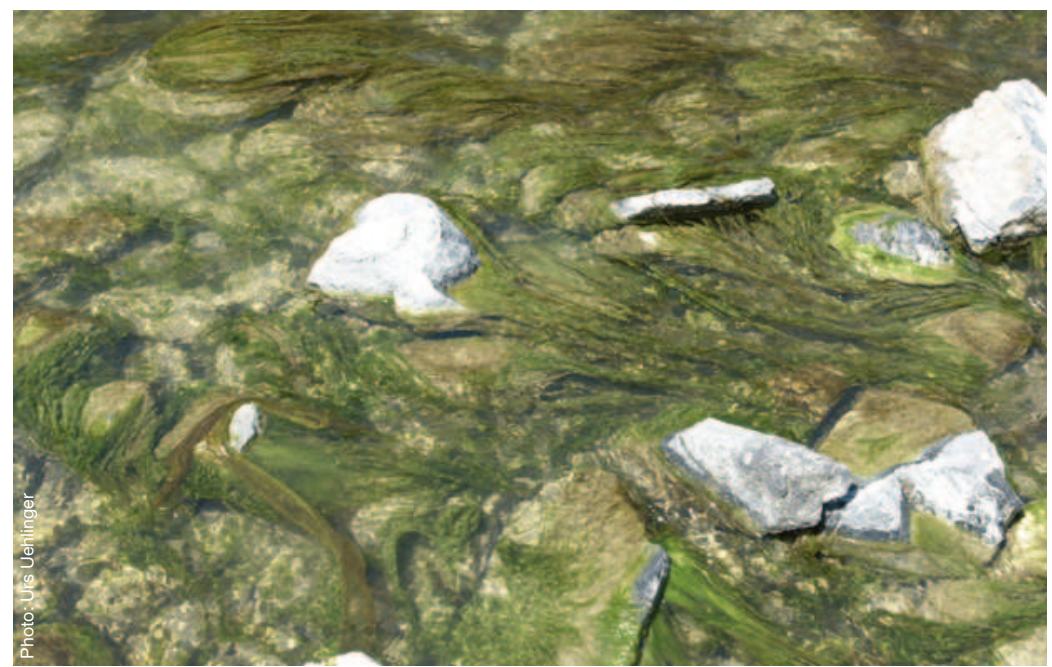

Figure 5. Algal and moss coverage on the river bottom of the Spöl River, Switzerland, before the flood program was initiated. Note the 'cementing' of the river bottom by fine sediments.

teria acknowledges the dynamic properties of rivers such as "natural" flow and temperature regimes and their role in sustaining biodiversity ${ }^{[4]}$. However, regimebased management should not be considered a cure for all degradations, as other biotic processes, namely migration and dispersal, so important for sustaining populations and their genetic integrity, are still constrained by river impoundment ${ }^{[19]}$.

Performing the paradigm shift in river restoration and management will likely be difficult and complex ${ }^{[1]}$, but as evidenced in the present case study of the Spöl River the feasibility and probability of success for attaining restoration goals are high. We suggest that regime-based criteria can be part of an adaptive management scheme for most regulated rivers, incorporating system-specific requirements, to enhance their ecological integrity while still meeting human needs.

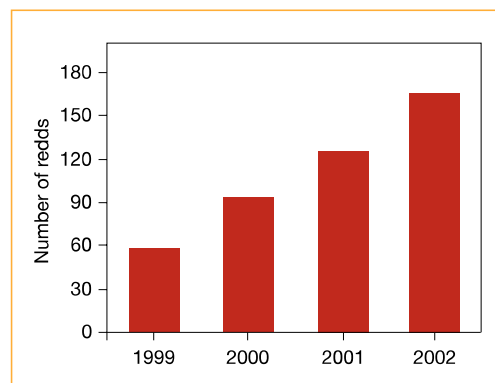

Figure 6. The number of redds (distinct local areas of stream bottom used for egg laying, fertilization and incubation) made by brown trout has increased substantially perimental floods as a result of the floods mobilizing bed sediments, reducing clogging, and thus increasing trout spawning potential in the river. Data figure reprinted with permission from Swiss Federal Institute for Environmental Science and Technology (EAWAG) ${ }^{[13] .}$ in the Spöl River, Switzerland, after the ex- 


\section{Acknowledgement}

We thank three anonymous reviewers for helpful comments that improved the paper.

\section{References}

[1] G.C. Poole, J.B. Dunham, D.M. Keenan, S.T. Sauter, D.A. McCullough, C. Mebane, J.C. Lockwood, D.A. Essig, M.P. Hicks, D.J. Sturdevant, E.J. Materna, S.A. Spalding, J. Risley, M. Deppman: "The Case for RegimeBased Water Quality Standards", Bioscience 54 (2004) 155-161.

[2] M. Dynesius, C. Nilsson: "Fragmentation and Flow Regulation of River Systems in the Northern Third of the World", Science 266 (1994) 753-762.

[3] J.A. Stanford, J.V. Ward, W.J. Liss, C.A. Frissell, R.N. Williams, J.A. Lichatowich, C.C. Coutant: "A General Protocol for Restoration of Regulated Rivers", Regulated Rivers: Research and Management 12 (1996) 391-413.

[4] N.L. Poff, J.D. Allan, M.B. Bain, J.R. Karr, K.L. Prestegaard, B.D. Richter, R.E. Sparks, J.C. Stromberg: "The Natural Flow Regime: A Paradigm for River Conservation and Restoration", Bioscience 47 (1997) 769-784.

[5] EUR-OP European Union Publications Office: "Directive 2000/60/EC of the European Parliament and of the Council of 23 October 2000 establishing a Framework for Community Action in the Field of Water Policy", Official Journal of the European Communities L.237 (2000) 1-72.

[6] B. Truffer, C. Bratrich, J. Markard, A. Peter, A. Wüest, B. Wehrli: "Green Hydropower: The Contribution of Aquatic Science Research to the Promotion of Sustainable Electricity", Aquatic Sciences 65 (2003) 99-110.

[7] E. Oud, T.C. Muir: "Engineering and Economic Aspects of Planning, Design, Construction and Operation of Large Dam Projects", in T. Dorcey (Ed.): Large Dams: Learning from the Past, Looking at the Future, Part II: Overview Papers, IUCN The World Conservation Union, Gland and the World Bank, Washington D.C. (1997), p. 17-39.

[8] C.M. Pringle: "Hydrological Connectivity and the Management of Biological Reserves: A Global Perspective", Ecological Applications 11 (2001) 981-998.

[9] E.J. Fittkau, F. Reiss: "Versuch einer Rekonstruktion der Fauna europäischer Ströme und ihrer Auen", Archiv für Hydrobiologie 97 (1983) 1-6.

[10] D.W. Reiser, M.P. Ramey, T.R. Lampert: Review of Flushing Flow Requirements in Regulated Streams, Bechtel Group, San Francisco, CA (1985).

[11] C.T. Robinson, U. Uehlinger, M.T. Monaghan: "Effects of a Multi-Year Experimental Flood Regime on Macroinvertebrates Downstream of a Reservoir", Aquatic Sciences 65 (2003) 210-222.

[12] U. Uehlinger, B. Kawecka, C.T. Robinson: "Effects of Experimental Floods on Periphyton and Stream Metabolism below a High Dam in the Swiss Alps (River Spöl)", Aquatic Sciences 65 (2003) 199-209.

[13] J. Ortlepp, U. Mürle: "Effects of Experimental Flooding on Brown Trout (Salmo trutta fario L.)", Aquatic Sciences 65 (2003) 232-238.

[14] H. Schmidt, F. Foeckler: "Geschiebereaktivierung im Hochrhein - eine entscheidende Maßnahme für das Flußökosystem", Natur und Mensch 1 (2003) 20-27.

[15] A. Bischoff, C. Wolter: "The Flood of the Century on the River Oder: Effects on the 0+
Fish Community and Implications for Floodplain Restoration", Regulated Rivers: Research and Management 17 (2001) 171-190.

[16] R.J. Naiman, R.E. Bilby, P.A. Bisson: "Riparian Ecology and Management in the Pacific Coastal Rain Forest", Bioscience 50 (2000) 996-1011.

[17] M. Zaleweski: "Ecohydrology - The Use of Ecological and Hydrological Processes for Sustainable Management of Water Resources", Hydrological Sciences Journal 47 (2002) 825-834.

[18] A. Jentsch, H. Wittmer, K. Jax, I. Ring, K. Henle: "Biodiversity - Emerging Issues for Linking Natural and Social Sciences", GAIA 12 (2003) 121-128.

(Submitted 6 May 2004, revised version accepted 15 July 2004; AJ.)

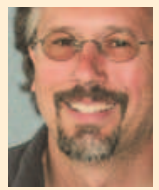

Christopher T. Robinson: Born 1960 in Ohio, USA. Studies in Disturbance Ecology (M.Sc. 1986, Michigan State University, USA). Doctorate in Stream Ecology (PhD, 1992), Department of Biology, Idaho State University, USA. Habilitation (PD, 2002), ETH Zürich, Switzerland. Presently, Senior Research Scientist with the Department of Limnology, Swiss Federal Institute for Environmental Science and Technology EAWAG, Dübendorf, Switzerland, and Privatdozent with the ETHZ. Primary research interests involve the ecology of alpine freshwaters.

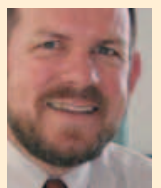

Peter Molinari: Born 1948 in Switzerland. Graduated ETH Zürich, Survey and Rural Engineering (1972). Engineer on various hydropower projects in SouthEast Asia (1975-1992). Since 1993 with the Engadiner Kraftwerke AG, Zernez, and Director since 1995. Swiss President and Board Member of Renewable Energy Certificate System (RECS), President Interest Group Hydropower (IGW), Vice President Association of Electric Power Companies of Grisons (VBE), Board Member Association of Swiss Power Companies (VSE) and Association of Environmentally Sound Electricity (VUE).

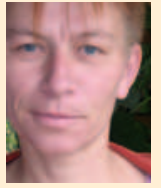

Uta Mürle: Born 1966 in Pforzheim, Germany. Education and work as a nurse (1988-1994). Studies at the University of Karlsruhe: Geo-ecology, Landscape Ecology, Soil Science, Water Chemistry, Hydrogeology, Geochemistry, Mineralogy (1994-2000). Diplom Geo-ecologist (2000). Since 2000, researcher with HYDRA Bureau for Freshwater Ecology, Öschelbronn, Germany. Primary emphasis: Stream Morphology, Management of Freshwater Ecosystems, Zoobenthos.

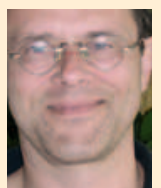

Johannes Ortlepp: Born 1956 in Suhl, Germany. Studies at the University of Freiburg, Germany: Limnology, Geobotany, Zoology, Soil Science; Diplom Biologist (1984). Studies on the biology of whitefish (Limnology Institute, University of Constance, Germany, 1984-1987). Biological-chemical investigation of streams (Water Resources Dept., Rottweil, Germany, 1990-1992). 19881996 researcher with HYDRA Institute for Applied Hydrobiology, Constance. Since 1996 Head of HYDRA Bureau for Freshwater Ecology, Öschelbronn, Germany. Primary emphasis: Fisheries, Zoobenthos, Restoration Ecology.

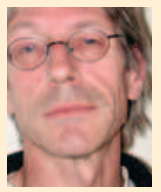

Thomas Scheurer: Born 1953 near Burgdorf, Switzerland. 1974-1980 studies in Geography, Geology, Anthropology at the University of Berne, Switzerland. $\mathrm{PhD}$ (Man and Biosphere project, Grindelwald, Switzerland, 1986). 1985-1995 employee in a private office for spatial planning and environmental impact studies. Coordinator for the Research Council of the Swiss National Park (since 1986), the Swiss Commission of Environmental Survey (1987-1993), the Inter-academic Commission for Alpine Studies (ICAS; since 1994), and the International Committee on Research in the Alps (since 1999).

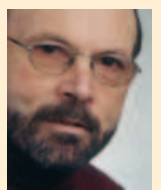

Urs Uehlinger: Born 1944 in Schaffhausen, Switzerland. Studies in Microbiology at ETH Zürich, Switzerland (Diplom 1973). PhD in Limnology (ETHZ 1980). Since 1981, Senior Research Scientist with the Department of Limnology at the Swiss Federal Institute for Environmental Science and Technology EAWAG, Dübendorf, Switzerland. Major research areas include ecosystem metabolism and organic matter dynamics in lotic ecosystems, and the ecology of alpine streams and floodplain rivers.

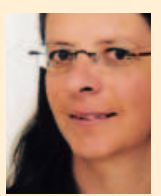

Margot Zahner Camenisch: Born 1963 in Schaffhausen, Switzerland. Studies at the University of Zürich, Switzerland, with a Diplom in Systematic Botany. Volunteer in diverse professional internships, and as research assistant for two years at the Geobotanical Institute, ETH Zürich. Since 1997, independent consultant with Martin Camenisch in an Ecobureau in Chur, Switzerland. 